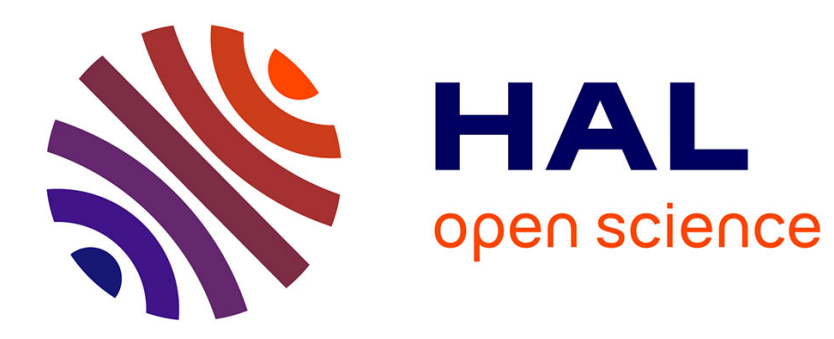

\title{
Long-Range Diffusion of Hydrogen in Amorphous Cu50Ti50
}

H. Mizubayashi, T. Ishii

\section{To cite this version:}

H. Mizubayashi, T. Ishii. Long-Range Diffusion of Hydrogen in Amorphous Cu50Ti50. Journal de Physique IV Proceedings, 1996, 06 (C8), pp.C8-659-C8-662. 10.1051/jp4:19968142 . jpa-00254575

\section{HAL Id: jpa-00254575 https://hal.science/jpa-00254575}

Submitted on 1 Jan 1996

HAL is a multi-disciplinary open access archive for the deposit and dissemination of scientific research documents, whether they are published or not. The documents may come from teaching and research institutions in France or abroad, or from public or private research centers.
L'archive ouverte pluridisciplinaire HAL, est destinée au dépôt et à la diffusion de documents scientifiques de niveau recherche, publiés ou non, émanant des établissements d'enseignement et de recherche français ou étrangers, des laboratoires publics ou privés. 


\title{
Long-Range Diffusion of Hydrogen in Amorphous $\mathrm{Cu}_{50} \mathbf{T i}$
}

\author{
H. Mizubayashi and T. Ishii \\ Institute of Materials Science, University of Tsukuba, Tsukuba 305, Japan
}

\begin{abstract}
The hydrogen Gorsky effects (HGE) measurements were carried out in amorphous $\mathrm{Cu}_{50} \mathrm{Ti}_{50}$ for which the data for the hydrogen Snoek peak (HSP) have been compiled. In the hydrogen concentration, $C_{\mathrm{H}}$, range below 1 at. $\%$, the hydrogen diffusion process changes over from the short circuit mode to the detrapping mode with increasing $C_{\mathrm{H}}$ and $(\mathrm{d} \lambda)^{2}$ is much smaller than $(\operatorname{tr} \lambda)^{2}$, where $\lambda$ is the strain tensor around a hydrogen atom. For $C_{\mathrm{H}}>1$ at.\%, the hydrogen diffusion proceeds by the detrapping mode. The whole hydrogen atoms contribute to the HGE although only hydrogen atoms sitting on the sites with $G$ being nearly equal to $\mu$ contribute to the HSP, where $G$ is the site energy and $\mu$ the chemical potential of hydrogen atoms. The results are expected as a dispersion in $G$ is much larger than thermal energies and the nearest neighbor blocking for hydrogen occupation is the case. $(\mathrm{d} \lambda)^{2}$ is much larger than (tr $\lambda)^{2}$, suggesting that one or two of $\lambda_{1}, \lambda_{2}$ and $\lambda_{3}$ is (are) negative for $C_{\mathrm{H}}>1$ at.\%.
\end{abstract}

\section{INTRODUCTION}

The anelasticity study of hydrogen $(\mathrm{H})$ in amorphous (a-) alloys has been ignited and stimulated by Berry and Pritchet [e.g., 1-5]. The hydrogen Snoek peak (HSP) reflecting the short range diffusion gives information about the local atomic structures and the hydrogen Gorsky effect (HGE) due to the long range diffusion provides insight into the site connectivity, respectively. The observed features, however, strongly depend on alloy compositions: For the relaxation strength of the HSP, reported are the almost linear increase with the concentration of hydrogen, $C_{\mathrm{H}}$, in $\mathrm{a}-\mathrm{Pd}_{\mathrm{x}} \mathrm{Si}_{100-\mathrm{x}}(\mathrm{x}=80,86[2-4])$, the camel like $C_{\mathrm{H}}$ dependence in $\mathrm{a}-\mathrm{Cu}_{50} \mathrm{Ti}_{50}$ and $\mathrm{a}-\mathrm{Cu}_{50} \mathrm{Zr}_{50}[6,7]$ and the intermediate behavior in a- $\mathrm{Co}_{33} \mathrm{Zr}_{67}[8]$, where the underlying process for the HSP is in dispute. The pre-exponential factor, $D_{\mathrm{G}, 0}$, of the chemical diffusion coefficient for the long range diffusion (here, for the HGE) also varies strongly depending on alloy compositions (see Fig.2(b) and [3-5, 9-12]). To pursue the systematic understanding of the behaviors of $\mathrm{H}$ atoms in a-alloys, we carried out the HGE measurements in a-Cu${ }_{50} \mathrm{Ti}_{50}$ for which the HSP data have been compiled.

\section{EXPERIMENTAL}

Amorphous $\mathrm{Cu}_{50} \mathrm{Ti}_{50}$ ribbons of $25 \mu \mathrm{m}$ thick and $1 \mathrm{~mm}$ wide were prepared by a melt spinning method in an Ar gas atmosphere. After mechanical polishing in water of the surface layer by $5 \mu \mathrm{m}$, hydrogen charging was made electrolytically in $0.1 \mathrm{~N} \mathrm{H}_{2} \mathrm{SO}_{4}$ at room temperatures. $C_{\mathrm{H}}$ in specimens was estimated by a vacuum extraction method. The HGE was measured as elastic after effects in bending strain in the temperature range between 320 and $340 \mathrm{~K}$, where the gage length of a specimen was about $20 \mathrm{~mm} . D_{\mathrm{G}, 0}$ and the activation energy, $E_{\mathrm{G}}$, in the chemical diffusion coefficient were estimated from the Arrhenius plot of the relaxation time for the HGE and the thickness of specimens. Because of the limited measurement temperature range, the experimental errors in $E_{\mathrm{G}}$ are as large as about $\pm 10 \%$. Examples of the errors in $D_{\mathrm{G}, 0}$ will be shown in Fig.2(b). The relaxation strength, $\Delta_{\mathrm{G}}$, of the HGE was estimated from the observed relaxation strength after taking into account an elapsed time for prestraining. See [9] for details. 


\section{RESULTS AND DISCUSSION}

\subsection{The Hydrogen Concentration Range above 1 at. $\%$}

Figure 1(a) shows the $C_{\mathrm{H}}$ dependence of $\Delta_{\mathrm{G}}$ observed in as-quenched $\mathrm{a}^{-} \mathrm{Cu}_{50} \mathrm{Ti}_{50}$ specimens, where the solid line 1 is drawn to guide eyes. In the $C_{\mathrm{H}}$ range above 1 at. $\%, \Delta_{\mathrm{G}}$ increases almost linearly with $C_{\mathrm{H}}$ showing a deviation at higher $C_{\mathrm{H}}$ For a dilute interstitial solid solution of crystalline materials, $\Delta_{G}$ can be written [13]

$$
\Delta_{\mathrm{G}}=\left(v_{0} E / 9 k_{\mathrm{B}} T \beta\right)(\operatorname{tr} \lambda)^{2} C_{0}
$$

where $v_{0}$ is an atomic volume, $E$ the Young's modulus, $k_{\mathrm{B}}$ the Boltzman factor, $\beta$ the number of interstitial sites per host atom in the lattice, and $\lambda$ the strain tensor around an interstitial atom, and $C_{0}$ the concentration of interstitial atoms. Using $\operatorname{tr} \lambda=0.11$ for $C_{H}$ below 20 at. $\%$ which is found after the dilatation measurements [14], $\beta=3.7$ which is reported for the tetrahedral sites in metalmetal a-alloys [15] and the appropriate values for other quantities [16, 17], the dashed line 2 in Fig. 1(a) is calculated assuming Eq.(1) and $C_{0}=C_{\mathrm{H}}$. The $\Delta_{\mathrm{G}}$ data observed in the $C_{\mathrm{H}}$ range between 1 and 10 at.\% show good agreement with the calculated values, suggesting that the whole $H$ atoms contribute to the HGE in the $C_{H}$ range. The deviation from the linear increase found for $C_{\mathrm{H}}>10$ at.\% will be mentioned later.

Figure 1(b) shows the $C_{\mathrm{H}}$ dependence of $\Delta_{\mathrm{R}} / \Delta_{\mathrm{G}}$ for $C_{\mathrm{H}}>1$ at. $\%$, where $\Delta_{\mathrm{R}}$ is the relaxation strength of the HSP observed in as-quenched a- $\mathrm{Cu}_{50} \mathrm{Ti}_{50}$ specimens; the curve 3 for the total $\Delta_{R}$ and the curve 4 for the $\Delta_{\mathrm{R}}-1$ of the predominant constituent HSP-1 ([6] and also see Fig.2(a)). $\Delta_{\mathrm{R}}$ being fairly larger than $\Delta_{\mathrm{G}}$ suggests that $(\delta \lambda)^{2}$ is much larger than $(\operatorname{tr} \lambda)^{2}$, i.e., one or two of $\lambda_{1}, \lambda_{2}$ and $\lambda_{3}$ should be negative. As a matter of fact, the X-ray and dilatation measurements [14] indicate that one or two of $\lambda_{1}, \lambda_{2}$ and $\lambda_{3}$ is (are) negative. The $C_{\mathrm{H}}$ dependence of $\Delta_{\mathrm{G}}$ being different from that of $\Delta_{\mathrm{R}}$ is emphasized. The camel like changes in $\Delta_{\mathrm{R}}$ suggest that only $\mathrm{H}$ atoms sitting on the sites with $G$ being nearly equal to $\mu$ can contribute to the HSP, where $G$ is the site energy and $\mu$ the chemical potential of $\mathrm{H}$ atoms [6-7].

Figures 2(a) and (b) show the $C_{\mathrm{H}}$ dependence of $E_{\mathrm{G}}$ and $D_{\mathrm{G}, 0}$, respectively. In Fig.2(a), the activation energies $E_{\mathrm{m}}(\mathrm{m}=0-5)$ reported for the constituent HSP-m are also shown, where the HSP-1 is always predominant and the constituent $\Delta_{\mathrm{R}}-\mathrm{m}$ for the HSP-m decreases in the order of $\mathrm{m}=1$ to 5 , and 0 [6]. For $C_{\mathrm{H}}>1$ at.\%, the values of $E_{\mathrm{G}}$ are similar to those of $E_{\mathrm{m}=1}$, where both $E_{\mathrm{G}}$ and $E_{\mathrm{m}=1}$ decrease with increasing $C_{\mathrm{H}}$. In Fig.2(b), the solid line 1 is drawn to guide eyes. The arrow 2 denotes the order of $D_{\mathrm{G}, 0}$ reported in $\mathrm{a}-\mathrm{Ni}_{40} \mathrm{Zr}_{60}$ [5] and $\mathrm{a}-\mathrm{Pd}_{\mathrm{x}} \mathrm{Si}_{100-\mathrm{x}}(\mathrm{x}=80,86$ [2-4], $\mathrm{x}=81,83$ [10]), the dashed line 3 the order of $D_{\mathrm{G}, 0}$ in crystalline $\mathrm{Cu}, \mathrm{Ni}, \mathrm{Pd}, \mathrm{Nb}, \mathrm{Ta}$ and $\mathrm{V}[18]$ and the arrow 4 the order of $D_{\mathrm{G}, 0}$ in a-Fe $\mathrm{Fe}_{40} \mathrm{Ni}_{40} \mathrm{P}_{14} \mathrm{~B}_{6}$ [11] and a-Pd ${ }_{73.2} \mathrm{X}_{8.2} \mathrm{Si}_{18}(\mathrm{X}=\mathrm{Ni}, \mathrm{Cu}, \mathrm{Ag}, \mathrm{Cr}, \mathrm{Fe}[12])$, respectively. The low value of $D_{\mathrm{G}, 0}$ indicated by the arrow 4 is suggested to reflect the existence of short circuits such as dislocations in crystalline materials [11]. On the other hand, the high value of $D_{\mathrm{G}, 0}$ indicated by the arrow 2 is surmised to suggest that $\mathrm{H}$ atoms sitting on the sites with $G \leqq \mu$ can migrate via the sites with higher $G$ and lower migration activation energies, i.e., detrapping motions $[2-4,9]$. The present values of $D_{\mathrm{G}, 0}$ found for $C_{\mathrm{H}}>1$ at.\% are comparable with $D_{\mathrm{G}, 0}$ indicated by the arrow 2 , and tend to decrease with increasing $C_{\mathrm{H}}$. The former result suggests that the long range diffusion of $\mathrm{H}$ atoms in $a-\mathrm{Cu}_{50} \mathrm{Ti}_{50}$ proceeds through detrapping motions. The latter is explained as a result of filling of $H$ sites from the bottom.

We discuss the different $C_{\mathrm{H}}$ dependence found for $\Delta_{\mathrm{G}}$ and $\Delta_{\mathrm{R}}$ at first. As already reported in a- 
$\mathrm{Cu}_{50} \mathrm{Ti}_{50}$ and $\mathrm{a}-\mathrm{Cu}_{50} \mathrm{Zr}_{50}[6,7]$, the camel like changes in $\Delta_{\mathrm{R}}$ can be expected when a dispersion in $G$ is much larger than thermal energies and $H$ atoms sitting on the sites with $G<\mu$ do not contribute to the HSP because of the nearest neighbor blocking for vacant sites due to nearby $\mathrm{H}$-atoms. In other words, a distribution of the density of active two level systems is narrow and located at around $G \sim \mu$. In contrast to the HSP, all the $\mathrm{H}$ atoms can contribute to the HGE because equilibration in the $\mathrm{H}$ occupation can be achieved for any sites through detrapping motions of $\mathrm{H}$ atoms. On the other hand, the deviatory decrease in $\Delta_{\mathrm{G}}$ found for $C_{\mathrm{H}}>10$ at.\% suggests that one part of $\mathrm{H}$ atoms hardly contributes to the HGE in the $C_{\mathrm{H}}$ range, because $\operatorname{tr} \lambda$ remains unchanged for $C_{\mathrm{H}}$ below 20 at.\% [14]. We surmise that detrapping motions of $\mathrm{H}$ atoms from the sites with lower $G$ are practically retarded due to an increase in activation energies of detrapping or geometrical blocking by an increase in number of nearby $\mathrm{H}$ atoms. When a dispersion in $G$ is not so large or a restriction for the site blocking is more moderate than for the nearest neighbor blocking, a linear increase in $\Delta_{R}$ can be expected. As a matter of fact, in a-Pd $\mathbf{S i}_{100-\mathrm{x}}(\mathrm{x} \sim 80)$ [2-4], the observed linear increase in $\Delta_{R}$ is suggested to reflect a moderate restriction for site blocking because of a dispersion in $G$ being much larger than thermal energies. For $a_{-}-\mathrm{Co}_{33} \mathrm{Zr}_{67}$ [8], we surmise that a restriction for site blocking is intermediate between those mentioned above because of the intermediate $C_{H}$ dependence of $\Delta_{R}$ reported.

For the HSP, the constituent HSP-m with lower activation energies than $E_{\mathrm{m}=1}$ are observed. On the other hand, $E_{\mathrm{G}}$ found in the HGE is similar to $E_{\mathrm{m}=1}$. The results suggest that the activation energies for detrapping motions for the HGE are nearly equal to $E_{\mathrm{m}=1}$ and that for the HSP, the constituent HSP-m ( $\mathrm{m}=0$ and 2 to 5$)$ with lower activation energies are not due to the detrapping motion but through migration between neighboring sites (see Fig.7 in [7]). For the constituent HSP-1, the further work is required to clarify whether the HSP-1 proceeds via migration between neighboring sites or the detrapping motion.

\subsection{The Hydrogen Concentration Range below 1 at. $\%$}

In Fig.1(a), 2(a) and 2(b) characteristic changes in $\Delta_{\mathrm{G}}, E_{\mathrm{G}}$ and $D_{\mathrm{G}, 0}$ can be seen for $C_{\mathrm{H}}$ below 1 at.\%; all the quantities show a steep increase followed by an abrupt decrease with increasing $C_{\mathrm{H}}$, suggesting that the underlying process for the HGE is different from that for $C_{\mathrm{H}}$ above 1 at.\%. The low values of $E_{\mathrm{G}}$ and $D_{\mathrm{G}, 0}$ found for $C_{\mathrm{H}}<0.2$ at. $\%$ are similar to those reported in a$\mathrm{Fe}_{40} \mathrm{Ni}_{40} \mathrm{P}_{14} \mathrm{~B}_{6}[11]$ and $\mathrm{a}-\mathrm{Pd}_{73.2} \mathrm{X}_{8.2} \mathrm{Si}_{18}(\mathrm{X}=\mathrm{Ni}$, $\mathrm{Cu}, \mathrm{Ag}, \mathrm{Cr}, \mathrm{Fe}$ [12]) suggesting the existence of short circuits for the long range diffusion. The steep increases in $E_{\mathrm{G}}$ and $D_{\mathrm{G}, 0}$ with increasing $C_{\mathrm{H}}$ are explained by a change in the diffusion process from the short circuit mode to the detrapping mode. Since no percolation path spanning the sites with $G \sim \mu$ is expected for such a low $C_{H}$ range, we surmise that some line defects such as dislocations in crystalline materials which have been
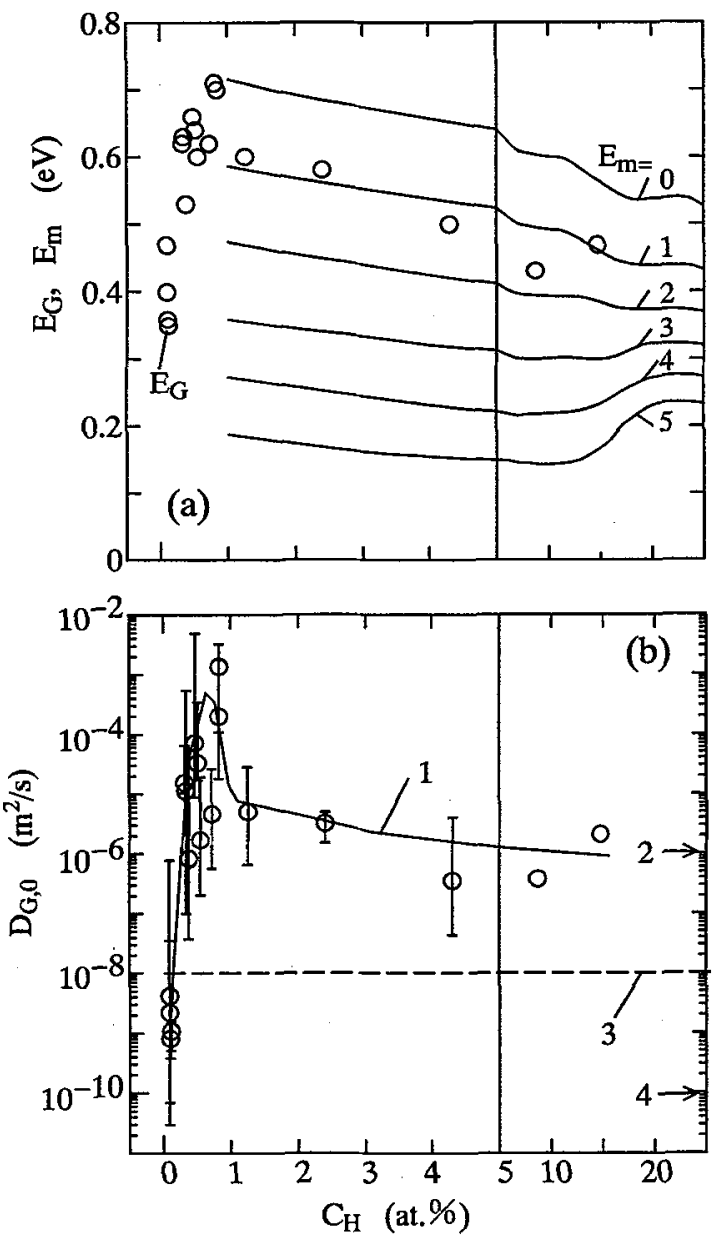

Figure 2: The $C_{\mathrm{H}}$ dependence of $E_{\mathrm{G}}$ (a) and of $D_{\mathrm{G}, 0}$ (b) observed in as-quenched a-Cu${ }_{50} \mathrm{Ti}_{50}$. See text. 
suggested in [11] serve as the short circuits. The steep increase in $D_{\mathrm{G}, 0}$ is explained by filling up of the sites in the line defects by $\mathrm{H}$-atoms. An increasing rate of $\Delta_{\mathrm{G}}$ with $C_{\mathrm{H}}$ found for $C_{\mathrm{H}}$ below 1 at. $\%$ is about 10 times larger than for $C_{\mathrm{H}}$ above 1 at.\%, suggesting a larger value of $(\operatorname{tr} \lambda)^{2}$ for $C_{\mathrm{H}}$ below 1 at. $\%$. On the other hand, such a strong increase in the HSP is not observed for $C_{\mathrm{H}}$ below 1 at.\% [6], suggesting that for the sites in the $C_{\mathrm{H}}$ range below 1 at. $\%,(\delta \lambda)^{2}$ is much smaller than $(\operatorname{tr} \lambda)^{2}$ and the maximum $\mathrm{H}$ content in the sites is about 1 at.\%. Since for $C_{\mathrm{H}}$ above 1 at.\%, $\mathrm{H}$ atoms occupy the tetrahedral sites in the order of $\mathrm{Ti}_{4}, \mathrm{Ti}_{3} \mathrm{Cu}_{1}$ and so on in $\mathrm{a}-\mathrm{Cu}_{50} \mathrm{Ti}_{50}$, we surmise that the sites responsible for $C_{\mathrm{H}}$ below 1 at.\% are the $\mathrm{Ti}_{6}$-octahedral sites.

\section{CONCLUSION}

The $C_{\mathrm{H}}$ range below 1 at. $\%$. The $\mathrm{H}$ diffusion process in a- $\mathrm{Cu}_{50} \mathrm{Ti}_{50}$ turns from the short circuit mode to the detrapping mode with increasing $C_{\mathrm{H}}$. For the $\lambda$ tensor around a $\mathrm{H}$ atoms, $(\delta \lambda)^{2}$ is much smaller than (tr $\lambda)^{2}$ in the $C_{\mathrm{H}}$ range. We surmise that the $\mathrm{H}$ sites in the $C_{\mathrm{H}}$ range are the $\mathrm{Ti}_{6}$-octahedral sites and some line defects serve as short circuits.

The $C_{\mathrm{H}}$ range above 1 at.\%: The $\mathrm{H}$ diffusion in $\mathrm{a}_{-} \mathrm{Cu}_{50} \mathrm{Ti}_{50}$ proceeds by the detrapping mode where $\mathrm{H}$ atoms are known to occupy the tetrahedral sites. The whole $H$ atoms contribute to the HGE although only $\mathrm{H}$ atoms sitting on the sites with $G \sim \mu$ contribute to the HSP. These results are expected as a dispersion in $G$ is much larger than thermal energies and the nearest neighbor blocking is the case. For the $\lambda$ tensor around a $\mathrm{H}$ atom in the $C_{\mathrm{H}}$ range, one or two of $\lambda_{1}, \lambda_{2}$ and $\lambda_{3}$ is (are) negative.

\section{Acknowledgements}

The authors are grateful to Dr. H. Tanimoto (Univ. of Tsukuba) for his invaluable helps on the course of experiments. This work is partly supported by a Grant in Aid for Scientific Research from the Ministry of Education, Science and Culture of Japan.

\section{References}

[1] Berry B.S., Pritchet W.C. and Tsuei C.C., Phys. Rev. Lett., 41(1978), 410.

[2] Berry B.S. and Pritchet W.C., Phys. Rev. B, 24(1981), 2299.

[3] Berry B.S. and Pritchet W.C., "Hydrogen in Disordered and Amorphous Solids", G. Bambakidis and R.C. Bowman, Jr. Eds. (Plenum Press, New York, 1985) p.219.

[4] Berry B.S. and Pritchet W.C., Z. Phys. Chem., 163(1989), 381.

[5] Berry B.S. and Pritchet W.C., Mater. Sci. Engng., 97(1988), 419.

[6] Mizubayashi H., Agari H. and Okuda S., Phys. Stat. Sol. (a), 122(1990), 221.

[7] Mizubayashi H., Naruse T. and Okuda S., Phys. Stat. Sol. (a), 132(1992), 79.

[8] Sinning H.-R., Phys. Stat. Sol. (a), 140(1993), 97.

[9] Mizubayashi H., Odai S. and Okuda S., Acta Metall. Mater., 42(1994), 561.

[10] Lee T.S. and Stevenson D.A., J. Non-Crystall. Solids, 72(1985), 249.

[11] Hofmann A. and Kronmüller H., Phys. Stat. Sol. (a), 104(1978), 619.

[12] Yoshinari O. and Kirchheim R., J. Less-Common Metals, 172-174(1991), 890.

[13] Nowick A.S, and Berry B.S., "Anelastic Relaxation in Crystalline Solids", (Academic Press, New York, 1972) p.302.

[14] Sibazaki M. and Mizubayashi H., to be published.

[15] Ninomiya T., "The Structure of Non-Crystalline Materials", P.H. Gaskell, J.M. Parken and E.A. Davis Eds. (Taylor and Francis Ltd., London, 1982) p.558.

[16] Tanner L.E., Davis L.A., Chen C.-P and Ray R., Scripta Metall,, 10(1976), 937.

[17] Grzeta B., Dini K., Cowlam N. and Davies H.A., J. Phys. F: Met. Phys., 15(1985), 2069.

[18] Völkl J. and Alefeld G., "Topics in Applied Phys. Vol.28", Hydrogen in Metals I, G. Alefeld and J. Völkl Eds. (springer-Verlag, Berlin, 1978), p.321. 